\title{
Evaluation of the Use of Information Systems: Objective and Subjective Measures Effectiveness Analysis
}

\author{
Karim Gassemi*, Siham Jabraoui, Merouane Bouhrouje \\ Ecole Nationale de Commerce et de Gestion de Casablanca, Casablanca Morocco. \\ * Corresponding author. Tel.: 00212661242948; email: k.gassemi@encgcasa.ac.ma \\ Manuscript submitted March 12, 2018; accepted June 1, 2018. \\ doi: 10.17706/ijeeee.2019.9.1.61-66
}

\begin{abstract}
According to many researchers, the degree of use of information systems is an important variable in the management information systems researchs field. The first objective of this research is to study the relationship between subjective (perceptual) and objective (system-generated) use measures for an information system. This research used e-mail as an information system. The model of Triandis was used as a theoretical basis to validate the operationalization of the theoretical framework. The results show that users have significantly overestimated their weekly frequency of e-mail usage by 2.36 uses, and that in future researchs to obtain a more accurate subjective assessment of the frequency of use the researchers should encourage the use of questions with absolute number answers. The study also demonstrated a positive relationship between the perceived consequences and use of an information system and between social factors and the use of an information system. Contrary to Triandis model, we did not find a significant relationship between facilitating conditions, the attitude and the use of an information system.
\end{abstract}

Key words: Information system evaluation, Triandis model, objective use, subjective use, theory of reasonned action.

\section{Introduction}

Measuring the success of information technologies has been one of the most studied subjects for several decades [1]-[3]. Many researchers suggest that the degree of use is one of the main variables according to which the assessment of the use of information system can be carried out. Despite the relatively high number of studies examining the use of information systems, there are fundamental differences in the conceptualization and operationalization of the degree of use of these systems which remains one of the major difficulties [4]-[6]. The aim of this research is to study and evaluate subjectives and objectives measures. An investigation of the differences between these measures can help us better understand the relationship between subjective and objective measures of use of an information system. This comparison will allow us to verify the assertion of Hartley, Brecht, Pagerey, Weeks, Chapanis and Hoecker [7], that a subjective method of use can have an impact on the evaluation process itself. We will also test to determine which of two subjective methods (Likert scale vs a frequency of use) is the most accurate. For practical reasons, we chose to study the use of e-mail because it enabled us to easily obtain a measure of the system's objective (system-generated) use by the different users. Moreover, several studies have already shown that the results concerning the use of e-mail can be generalized to other information systems [8], [9].

\section{Literature Review}


The level of use is one of the main variables that can inform the degree of success of setting up an information system [10], [11]. Several studies have examined the various determinants of intention to use, which in turn determine effective use [8], [12], [13].

Several researchers are satisfied with the subjective evaluations of the users, obtained by questionnaires or interviews [11], [14]-[20]. The majority of these studies, researchers simply ask respondents about their use of the information system. The literature review in behavioral psychology orients us to analyze the intention as an important factor in the evaluation of an information system. In this research, we rely on two theoretical frameworks: The Theory of Rational Action (TRA) and the Theory of Planned Action (TPA).

The behavioral intent within the framework of the Theory of Action [21] is explained on the one hand by the attitude which is defined as the favorable or unfavorable evaluation of the person against the achievement of a given behavior. On the other hand, it is explained by the subjective norms which correspond to the respect that the person gives to the recommendations of the individuals who count for it in view of his own behavioral realization. The theory of reasoned action is based on two main principles. The behaviors is such that the actor has sufficient control over the task to be performed [22]. The second is that the person behaves rationally and takes into account the information available to make the decision. In this context, behavior is considered planned and reasoned.

According to Venkatesh and Bala [12], subjective norms affect the use intent significantly more in a context of duty obligation even if the effect takes a downward trend over time. The process of social influence, on the other hand, reflects the pressure exerted on the individual by his group of belonging through the phenomenon of conformity which results in (1) complacency, (2) Image and social status of the individual that it seeks to continually improve and (3) internalization, which refers to saying that if the user's entourage suggests that a new technology may prove useful, the use of this technology can be seen as being actually useful [10], [23].

\section{Research Model and Hypothesis}

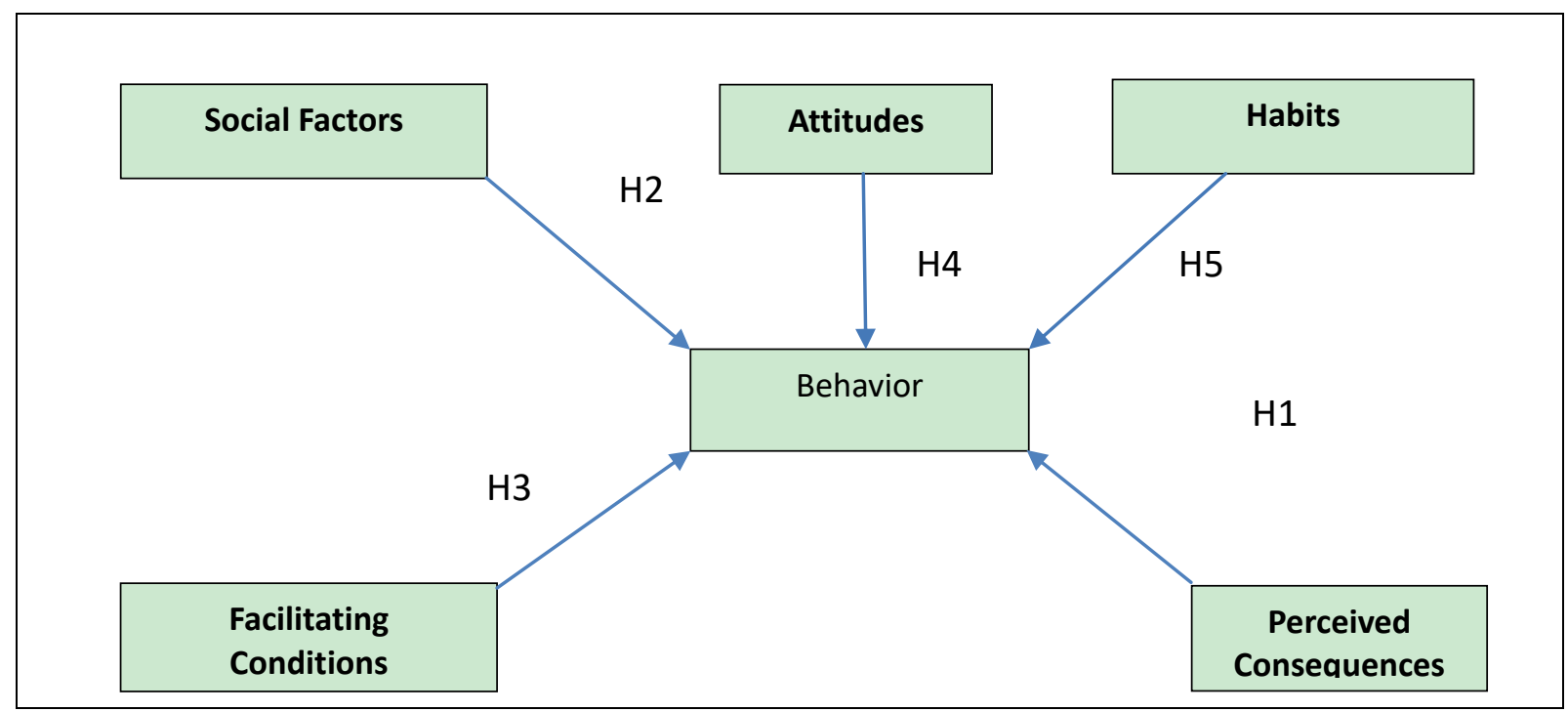

Fig. 1. Research model.

Several researchers in information systems have adopted the theory of Ajzen and Fishbein [21]. This theory, widely used in sociology and psychology, has shown certain shortcomings with regard to the influence of intentions on behavior. Subsequently, Triandis [24], [25] proposed a more complete model based on the concepts of the theory of Azjen and Fishbein [21]. The research model (Fig. 1) that was used 
for this study is an adaptation of the Triandis model [25]. This model indicates that the behavior of individuals can be determined by what they would like to do (Attitudes), By what they think they should do (Social Factors) and by the experience they have acquired (habits). Behavior may also be influenced by the Perceived Consequences of the act performance. If the individual perceives the consequences as beneficial to him, he will reinforce his behavior and vice versa. The behavior is also influenced by Facilitating

\section{Conditions.}

Behavior (use will be assessed in three ways: 1 subjective assessment of use with Likert-type seven-level questions, (2) a subjective assessment where the respondent must indicate his / her weekly average frequency of use and (3) the objective frequency of use (provided by the system). The evaluation of the use of e-mail in three different ways will also allow us to better understand and be able to analyze the relationships that exist between subjective and objective measures.

H1: There is a positive relationship between the perceived consequences and the frequency of e-mail use.

$\mathrm{H} 2$ : There is a positive relationship between social factors and the frequency of use of e-mail.

H3: There is a positive relationship between the facilitating conditions and the frequency of use of e-mail.

$\mathrm{H} 4$ : There is a positive relationship between the attitude of individuals and the frequency of e-mail use.

H5: There is a positive relationship between the habits and frequency of use of e-mail.

\section{Data Analysis and Results}

Table 1. Pearson Correlation $\left(n=135^{* *} p<.001 * p>.001\right)$

\begin{tabular}{|c|c|c|c|}
\hline Variable & Subjective use r/p & Frequency of subjective $\mathbf{r} / \mathbf{p}$ & Frequency of objective $\mathbf{r} / \mathbf{p}$ \\
\hline Perceived & $0,31^{* *}$ & $0,30^{* *}$ & $0,29^{* *}$ \\
Consequences & .000 & .000 & .000 \\
(Hypothsis 1) & $0,27^{* *}$ & $03,2^{* *}$ & $0,21^{*}$ \\
Social factors & .001 & .000 & -017 \\
(Hypothesis 2) & 0,13 & 0,08 & $-0,06$ \\
Facilitating & .199 & .432 & $-0,01$ \\
Conditions & 0,09 & $-0,03$ & .861 \\
(Hypothesis 3) & .277 & .726 & $-0,11$ \\
Attitude (Hypothesis & $0,20^{*}$ & 0,16 & .219 \\
4) & .019 & .066 & .219 \\
Habits (Hypothesis & & & \\
\hline 5) & & & \\
\hline
\end{tabular}

The data were collected through a questionnaire administered to more than 500 students at Laval University (Quebec, Canada). We used a probabilistic sampling methodology. The return rate is $28 \%$. The constructs of the research model were validated with a factor analysis, as a main component. The items forming the constructs are presented in Table 1. For this factor analysis we used the varimax rotation option. The main component factor analysis confirms well the 4 constructs of our study, namely, The Perceived Consequences, Social Factors, Facilitating Conditions and Attitude. To verify the validity of constructs, the cronbach alpha coefficient (1971) was calculated. The results show that the constructs are very homogeneous since the alpha is always very high. It is 0.81 for the perceived consequences, 0.84 for the social factors, 0.96 for the facilitating conditions and 0.94 for the attitude. Assumptions associated with the research model were verified using Pearson correlations with a minimum significance level of 0.01 . Statistics shows that there is a significant difference of 1.58 on a scale of $7(22.4 \%)$ between subjective and objective use. Concretely, this indicates that for a respondent a great use of an e-mail can correspond to once a day while for other respondents it is much more. It is also noted that after recoding on a 7-level comparative scale, there is no significant difference between the subjective frequency of use and the objective frequency. However, a significant difference of 1.52 between subjective use and frequency 
objective. This implies that the use of a question that requires the frequency of use in absolute numbers is more precise than a question that asks for the frequency of use on a Likert scale. So in future research, to obtain a better accuracy of the subjective evaluation of the frequency of use the researchers should favor the use of questions with answers in absolute number.

The results concerning the facilitating conditions and the attitudes are not significant contrary to what the model of Triandis [24], [25] predicted us. On the other hand, they correspond to the results obtained by Thompson et al. [26]. As for the facilitating conditions, Once the adaptation period has passed, the use of an e-mail message may not be complex enough so that the impact of the facilitating conditions has an influence on the frequency of the use. As far as attitude is concerned, the use of e-mail does not appear to generate very strong emotion on users, as Thompson et al. [26] in their study of PC use. The correlation between habits (experience) and evaluation of subjective use is significant. However, it is not significant with subjective frequency of use and frequency of objective use. User can get through the use of an e-mail is not directly related to the frequency of use. It may therefore be thought that the experienced user will have established a certain usage habit that will maximize the results according to its needs. In other words, it will probably have reached saturation with regard to its frequency of weekly use.

\section{Conclusion}

In this study we used an approach, suggested by several researchers, which allows to obtain accurate statistics on the actual use of Information systems. The results show that the use of a question that demands the frequency of subjective use in absolute numbers is more accurate than that using a Likert scale. Moreover, despite the fact that users have overvalued their use, Show that for the validation of the research hypotheses, the results obtained with the subjective evaluations correspond with those obtained with the objective measurements except for the evaluation of the subjective use of the habits which does not correspond significantly with the evaluation of subjective and objective frequency of use. For organizations, the results of this study are very relevant as they will enable practitioners to design and use even more efficient and accurate tools for evaluating their information systems. It is therefore important to continue to carry out additional research in several sectors of activity in order to better validate the operationalization of subjective measures and to better understand the relationship between subjective and objective measures of use. This better understanding of the measures will allow us to better advise manager in the choice of the subjective measures that he can use to make more effective evaluation information system use.

\section{Acknowledgment}

This study could not be completed without the help of the students and IT department of laval University. The acknowledgement also goes to the different members of the research unit LAMSO (Marketing and strategy Analysis) within the ENCG Casablanca.

\section{References}

[1] Urbach, D. W. I. N., Smolnik, S., \& Riempp, G. (2009). The state of research on information systems success. Business \& Information Systems Engineering, 1(4), 315-325.

[2] Ajzen, I. (1991). The theory of planned behavior. Organizational Behavior and Human Decision Processes, 50(2), 179-211.

[3] Swanson, E. B. (1987). Information channel disposition and use. Decision Sciences, 18(1), 131-145.

[4] Hornbæk, K. (2006). Current practice in measuring usability: Challenges to usability studies and research. International Journal of Human-Computer Studies, 64(2), 79-102. 
[5] Debue, N., Hellemans, C., \& Leemput, C. (2013). Acceptabilité des sites web et ergonomie de l'interface: éTude de l'influence de l'utilisabilité objective et de la charge cognitive. Revue des Interactions Humaines Médiatisées, 14(2), 1-24.

[6] Venkatesh, V., \& Davis, F. D. (2000). A theoretical extension of the technology acceptance model: Four longitudinal field studies. Management Science, 46(2), 186-204.

[7] Hartley, B. M., Pagerey, P., Weeks, G., Chapanis, A., \& Hoecker, D. (1977). Subjective time estimates of work tasks by office workers. Journal of Occupation Psychology, 50, 23-36.

[8] Davis, F. D. (1989). Perceived usefulness, perceived ease of use, and user acceptance of information technology. MIS Quarterly, 319-340.

[9] Hendrickson, A. R., Massey, P. D., \& Cronan, T. P. (1993). On the test-retest reliability of perceived usefulness and perceived ease of use scales. MIS Quarterly, 227-230.

[10] DeLone, W. H., \& McLean, E. R. (2002, January). Information systems success revisited. Proceedings of the 35th Annual Hawaii International Conference on System Sciences (pp. 2966-2976). IEEE.

[11] Delone, W. H. (1988). Determinants of success for computer usage in small business. MIS Quarterly, 12(1), 51-61.

[12] Venkatesh, V., \& Bala, H. (2008). Technology acceptance model 3 and a research agenda on interventions. Decision Sciences, 39(2), 273-315.

[13] Venkatesh, V., Morris, M. G., Davis, G. B., \& Davis, F. D. (2003). User acceptance of information technology: Toward a unified view. MIS Quarterly, 425-478.

[14] Adams, A. D., Nelson, R. R., \& Todd, P. A. (1992). Perceived usefulness, ease of use of use, and usage of information technology: A replication. MIS Quarterly, 227-247.

[15] Bergeron, F. (1986). Factors influencing the use of DP charge-back systems from a user's perception. MIS Quarterly, 10(3), 225-237.

[16] Davis, F. D., \& Venkatesh, V. (2004). Toward preprototype user acceptance testing of new information systems: Implications for software project management. IEEE Transactions on Engineering Management, 51(1), 31-46.

[17] Chin, W. W., \& Gopal, A. (1995). Adoption intention in GSS: Relative importance of beliefs. ACM SigMIS Database, 26(2-3), 42-64.

[18] Brangier, E., Hammes-Adelé, S., \& Bastien, J. M. (2010). Analyse critique des approches de l'acceptation des technologies: de l'utilisabilité à la symbiose humain-technologie-organisation. Revue Européenne de Psychologie Appliquée/European Review of Applied Psychology, 60(2), 129-146.

[19] Davis. (1989). Fred perceived usefulness, perceived ease of use, and user acceptance of information technology. MIS Quarterly, 13, 319-339.

[20] Trice, A. W., \& Treacy, M. E. Utilization as a dependent variable in MIS research, database.

[21] Ajzen, I., \& Fishbein, M. (1980). Understanding attitudes and predicting social behavior, prentice. Hall, Englewood Cliffs, N.J.

[22] Wood, R., \& Bandura, A. (1989). Social cognitive theory of organizational management. Academy of Management Review, 14(3), 361-384.

[23] Annett, J. (2002). Subjective rating scales: Science or art? Ergonomics, 45(14), 966-987.

[24] Triandis, H. C (1980). Values, attitudes, and interpersonal behavior, Nebraska symposium on motivation, 1979, beliefs. Attitudes and Values, 195-259. University of Nebraska Press, Lincoin.

[25] Triandis, H. C. (1971). Attitude and Attitude Charge. John Wiley and Sons, Inc., New York, NY.

[26] Trice, A. W., \& Treacy, M. E. (1986). Utilization as a dependent variable in MIS research. Data Base, 33-41. 


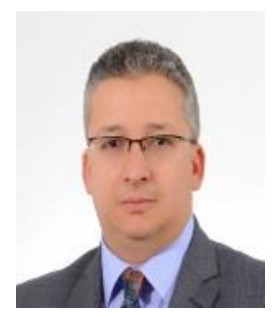

Karim Gassemi is a full professor joining the university in 2007, where he served as professor of Management and Corporate Strategy at the ENCG Casablanca. Dr. Gassemi held a PhD degree From Pantheon Assas University and an MBA from Laval University. He is also in charge of the LAMSO unit research. The recipient of numerous professional awards, Gassemi has published dozens of articles. He is also the coauthor of book, "Understanding The use and development of e-government platform in developing countries". Dr. Gassemi's recent research focuses on information system use, Corporate Strategy and the Networking Performance.

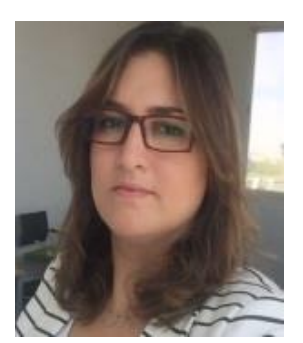

Siham Jabraoui is a full professor joining the university in 2011, where he served as professor of management information system at the ENCG Casablanca. Dr. Jabraoui Hold a PhD Degree from Versailles University. Jabroui has scientific contributions in field of information system integration. Dr. Jabraoui's recent research focuses on information system integration, ERP and Customer Relationship Management system.

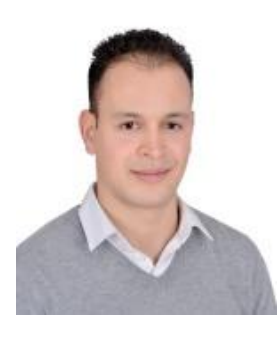

Merouane Bouhrouje is a PhD student enrolled at the LAMSO Unit research. His main research focuses on the technology acceptance and the use of information system. He is also an information system consultant and manages IT integration projects. 